\title{
Case report: an acute infarct in the left caudate and lentiform nuclei secondary to bacterial meningitis
}

\begin{abstract}
Bacterial meningitis has an annual rate of 1.2 million cases per year and if not diagnosed quickly, it can result in long term sequala and in some cases, death. In some instances, patients can develop a hemiparesis secondary to infarction and cranial nerve palsy. Although most cases are transient, it is important for clinicians to recognize potential sequalae while treating patients with meningitis. We report a case of an 18-year-old female who presented to our service after a motor vehicle accident. Upon further investigation it was found that she was suffering from bacterial meningitis. The patient subsequently developed a left caudate infarct which caused hemiparesis of her right side.
\end{abstract}

Volume 9 Issue 6 - 2019

\author{
Ronald Harrison,' Richard Giovane ${ }^{2}$ \\ 'Department of Family Medicine, University of Alabama, USA \\ ${ }^{2}$ Department of Family Medicine, LV Stabler Hospital, USA
}

Correspondence: Richard Giovane, Resident Physician,

Department of Family Medicine, 80I Campus Drive, Tuscaloosa, Alabama, 35487, USA, Tel 917-993-2794,

Email richargiovane357@gmail.com Received: September 23, 2019 | Published: November 14,
2019

\section{Case report}

We report a case of an 18-year-old female with no past medical history who presented to the emergency room after a motor vehicle accident. On initial presentation, the patient was found by local authorities after the motor vehicle accident. She was incoherent and referring to herself as a "butterfly". It was found, per family, that one day before this incident the patient felt "sick" and began vomiting. The vomiting continued throughout the day despite having Ondansetron given to her by her primary care physician with intent of the patient following up in clinic the next day. The patient also complained of a headache, which did not respond to acetaminophen. The patient was on route to the follow up appointment when the motor vehicle accident occurred. While examined in the emergency room, the patient had altered mental status as indicated that the patient was not orientated to person, place, time or situation with slow response to questioning. On physical exam, other than the obvious altered mental state, there were no other focal abnormalities. The patient was afebrile and had normal vital signs. Initial laboratory work revealed a white blood cell count of $29.4 \times 10^{\wedge} 3 / \mathrm{uL}$, and Neutrophil count of $92.6 \times 10^{\wedge} 3 / \mathrm{uL}$ with a total Absolute Neutrophil count of $27.30 \times 10^{\wedge} 3 /$ $\mathrm{uL}$. Urine toxicology was negative. Blood cultures were drawn and were subsequently found to be negative after 72 hours. A CT scan of the head in the emergency room, revealed bilateral sinusitis without evidence of intracranial abnormalities. A lumbar puncture was also done which showed cloudy fluid, WBC 600/ uL, RBC 1451/uL, with a WBC differential of polynuclear WBCs of $77.0 \%$ and lymphocytes of $16.0 \%$. No xanthochromia was present. CSF Glucose $<10 \mathrm{~L}$, CSF total protein of 324. Culturing of the CSF showed that it was negative for HSV, Hemophilus, N. meningitidis, E.coli, Group B Strep. and S. pneumoniae.

The Patient was transferred to the ICU for suspected bacterial meningitis and she was started on IV fluids along with Ceftriaxone, Vancomycin and Acyclovir. On the first night of the patient's admission, the she was re-examined and appeared to be worsening. This was since she was still incoherent, she did not open her eyes to command and would only squeeze with her left hand. However, the patient did display purposeful movements with her left side only. When examined, the patient would pull the hospital bed sheet covers back over her only with her left side. With the worsening right sided weakness, it was then decided to obtain a head/brain MRI. This was attempted during initial presentation in the emergency room, however patient was too agitated to effectively obtain an accurate image. Therefore, during the second attempt, the patient was given the patient morphine and lorazepam to reduce agitation to get a stat MRI without contrast. The MRI without contrast was suggestive of meningitis, in addition to an acute infarct in the left caudate and lentiform nuclei, extending into the mesial temporal lobe. In discussion with the on-call radiologist; there were no signs suggestive of increased intracranial pressure, but it was confirmed that there was an acute infarct of the left mesial temporal lobe. Given this information, it was decided to transfer the patient to a level one care center. IV Clindamycin was recommended to be started on top of the current regime, by the accepting physician for broader coverage. No anti-fungal therapy was initiated as it was discussed that the patient did not have risk factors for developing fungal meningitis.

\section{Discussion}

Bacterial meningitis has an annual rate of 1.2 million cases per year and causes 135,000 deaths per year. ${ }^{1}$ If not recognized early, it can lead to severe complications such as seizures, intellectual impairment, neurological deficits and death. ${ }^{2}$ Although neurological complications occur in as many as $20 \%$ of those affected with bacterial meningitis, most of the complications are transient and include hearing loss, cranial nerve palsy and speech impairment. ${ }^{3,4}$ Patients who are at risk of developing neurological complications are those who present with hypotension, altered mental status, seizures or a delay in antibiotic therapy, which had the highest association in poor outcomes. ${ }^{4}$ In less than $10 \%$ of meningitis cases, ${ }^{5}$ hemiparesis or quadriparesis can develop due to infarction or arterial spasms. ${ }^{5}$ Although the mechanism of action is unclear of the infarct, it is thought to be due to a local vasculitis, septic emboli or the development of coagulopathy. ${ }^{6}$ With most complications of bacterial meningitis, the focal paresis is transient in most cases and does resolve by the time the patient is discharged. ${ }^{5}$ Stroke, secondary to meningitis does have a higher association with patient mortality and longterm complications. ${ }^{6}$

\section{Conclusion}

Bacterial meningitis can pose fatal consequences if not diagnosed accurately and treated appropriately. In some instances, despite a clinician's best effort; sequalae such as infarction can develop which will worsen the patient's quality of life. Although most complications 
from infarction are transient and patients recover, it is important for the clinical to understand potential compilations despite best clinical practices.

\section{Acknowledgments}

None.

\section{Conflicts of interest}

The authors did not report any potential conflicts of interest.

\section{Funding}

None.

\section{References}

1. Scheld WM, Koedel U, Nathan B, et al. Pathophysiology of bacteria meningitis: mechanism(s) of neuronal injury. JInfect Dis. 2002;186Suppl 2:S225-S233.
2. Pfister HW, Feiden W, Einhäupl KM. Spectrum of complications during bacterial meningitis in adults. Results of a prospective clinical study. Arch Neurol. 1993;50(6):575-581.

3. Durand ML, Calderwood SB, Weber DJ, et al. Acute bacterial meningitis in adults. A review of 493 episodes. $N$ Engl J Med. 1993;328(1):21-28.

4. Aronin SI, Peduzzi P, Quagliarello VJ. Community-acquired bacterial meningitis: risk stratification for adverse clinical outcome and effect of antibiotic timing. Ann Intern Med. 1998;129(11):862-889.

5. Van de beek D, De gans J, Spanjaard L, et al. Clinical features and prognostic factors in adults with bacterial meningitis. $N$ Engl J Med. 2004;351(18):1849-1859.

6. Bodilsen J, Dalager-pedersen M, Schønheyder HC, et al. Stroke in community-acquired bacterial meningitis: a Danish population-based study. Int J Infect Dis. 2014;20:18-22. 